\title{
Impact Strength of Acrylic Denture Base Resin Reinforced with Woven Glass Fiber:
}

\author{
Takahito KANIE, Hiroyuki ARIKAWA, Koichi FUJII \\ and Seiji BAN \\ Department of Biomaterials Science \\ Kagoshima University Dental School \\ 8-35-1 Sakuragaoka, Kagoshima 890-8544, Japan
}

Received September 26, 2002/Accepted December 25, 2002

\begin{abstract}
This study investigated the effect of the number and position of woven glass fibers in denture base resin matrix on its impact strength. Test specimens were reinforced with woven glass fiber $0.5,1.0$, or $1.5 \mathrm{~mm}$ below the surface. The impact strength was tested using an Izod-type impact tester with an impact speed of $335 \mathrm{~cm} / \mathrm{s}$, which simulates dropping the denture, and using a flywheel-type impact tester with a two-point support at 13.5 and $75.0 \mathrm{~cm} / \mathrm{s}$, which simulates the chewing. The woven glass fibers had a strengthening effect in all tests, and the impact resistance was further improved when the woven glass fibers were positioned more superficially in the resin. The results suggest that woven glass fiber is an effective reinforcement in denture base resin.
\end{abstract}

Key words: Denture base resin, Woven glass fiber, Impact strength

\section{INTRODUCTION}

Acrylic denture base resin sometimes cracks in the median line during chewing or when dentures are accidentally dropped. Such breakage often originates from an impulsive force. Therefore, studies have examined ways to improve the impact strength of resins. The matrix resin can be strengthened by chemical modification through the addition of a poly-functional monomer or another monomer ${ }^{1-5)}$ or by using fiber reinforcement ${ }^{6-13)}$. Study ${ }^{4)}$ has shown that the addition of dimethacrylate monomers to the substrate improves the impact resistance of denture base resin by $50-70 \%$, while another study ${ }^{5)}$ of poly-functional monomers did not find any improvement in impact resistance.

In contrast, polyethylene fiber reinforcement was reported to improve the impact resistance by $360 \%{ }^{13)}$, and carbon fiber reinforcement increased the impact strength greater than 10 -fold that of $\mathrm{PMMA}^{7)}$. Currently, metal wires are generally used as reinforcements. However, metal wire is often difficult to work, and can produce an inferior result esthetically. The mechanical properties of the other effective fibers, such as carbon, nylon, and polyethylene, have been discussed; however, the effectiveness of the fiber reinforcement depends on many variables, e.g. type, position and direction of fibers.

Recently, studies ${ }^{14,15)}$ have examined glass fiber reinforcement. Dental resin 
readily adheres to glass fiber and the esthetic results are excellent. The glass is light compared with metal. One previous study ${ }^{16)}$ suggested that the flexural strength of denture base resin is improved when it is reinforced with woven glass fiber. However, few studies ${ }^{17-19)}$ have examined the impact strength of denture base resin reinforced with glass fiber, since glass, which is a brittle material, is generally thought to be too weak to survive impact. This study investigated the effect of the number and position of woven glass fibers in the matrix resin on the impact strength under two different impact testers.

\section{MATERIALS AND METHODS}

\section{Manufacture of test specimens}

The woven glass fiber (YEA2306, Mie Fabrics, Mie, Japan) used in this study consisted of E-glass and was $0.23 \mathrm{~mm}$ in standard thickness (Fig. 1). The woven glass fiber was cleaned in boiling water for $1 \mathrm{hr}$, dried in air, cut into $40 \times 100-\mathrm{mm}$ sheets, and then soaked in 2\%- $\gamma$-MPTS (Shinetsu Chemicals, Tokyo, Japan)-ethanol solution for $10 \mathrm{~min}$ to silanize it. Then, it was dried in air for $3 \mathrm{hr}$, and heated at $115^{\circ} \mathrm{C}$ for $10 \mathrm{~min}$. Then, 1 or 2 sheets of the silanized woven glass fiber were sandwiched between two Teflon boards and sealed with aluminum foil. BPO was added to the liquid denture base resin monomer (Pour Resin, Shofu Inc., Kyoto, Japan) at 1 wt\% and injected into the space containing the woven glass fiber and allowed to polymerize into a thin plate with an average thickness of 0.31 or $0.56 \mathrm{~mm}$ (one or two layers of woven glass fiber; Codes: $\mathrm{S}$ and $\mathrm{D}$ ) by heating at $50^{\circ} \mathrm{C}$ for $30 \mathrm{~min}$. Then, the thin plate was put in a concave Teflon mold and a mixture in a powder/liquid ratio of 9 $\mathrm{g} / 5 \mathrm{ml}$ was poured into the Teflon mold. This was heated at $50^{\circ} \mathrm{C}$ for $30 \mathrm{~min}$. After polymerization, the composite block was cut with a diamond blade, and polished to $3.2 \pm 0.1 \mathrm{~mm}$ thickness, $3.6 \pm 0.1 \mathrm{~mm}$ width, and $70 \mathrm{~mm}$ length. The details of this process were described in a previously ${ }^{16)}$. The reinforcing glass fibers were positioned

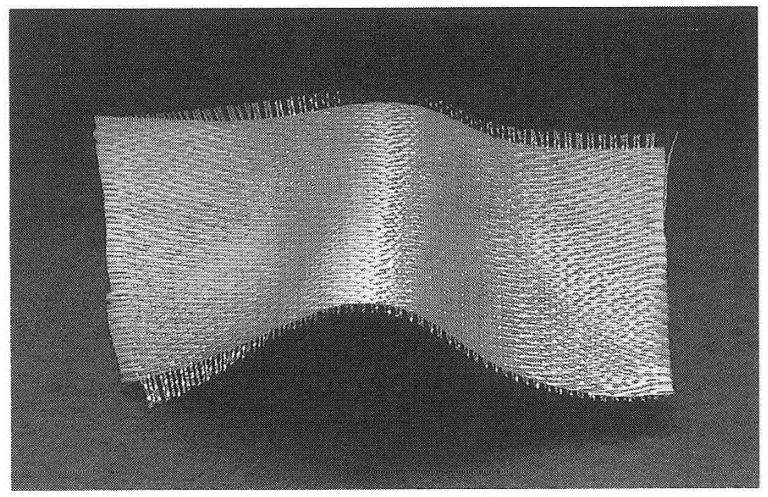

Fig. 1 Woven glass fiber used in this investigation. 


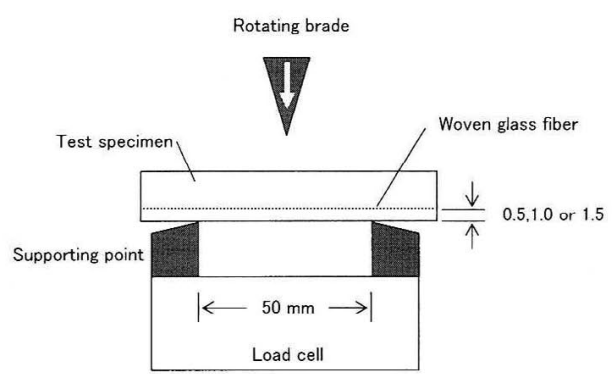

Fig. 2 Testing method of the flywheel type impact-testing machine.

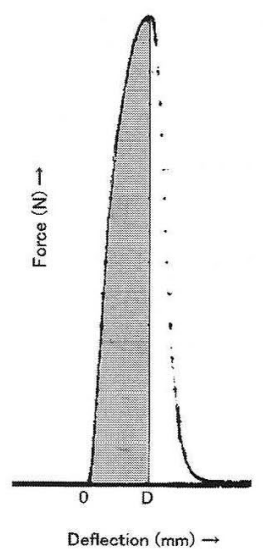

Fig. 3 Typical trace of load-deformation curve measured by the flywheel type impact-testing machine.

$0.5,1.0$, or $1.5 \mathrm{~mm}$ below the surface of the test specimens (Codes: $-05,-10$ and $-15)$.

\section{Impact test}

A flywheel type impact-testing machine (Thrive Seiko, Kagoshima, Japan) with twopoint support and an Izod impact tester (Shimadzu, Kyoto, Japan) were used to obtain two impact conditions. The flywheel type impact-testing machine was used for measurements at impact speeds of 13.5 and $75.0 \mathrm{~cm} / \mathrm{s}$; the former corresponds to the speed during chewing, and the latter is the maximum speed of this tester (Fig. 2). The span length was $50 \mathrm{~mm}$ and the force-deflection curve obtained in the impact test was recorded with a pen-recorder. The absorbed energy $\left(\mathrm{E}_{\mathrm{a}}\right)$ of the test specimen was calculated using the equation ${ }^{20)}$ :

$$
\mathrm{E}_{a}=\int_{0}^{\mathrm{D}} f d x
$$

where $D$ is the deflection at the maximum load point. In the equation, $\int f d x$ corresponds to the solid area under the curve in Fig. 3. The area was calculated using computer software (WinRoof, Mitani, Fukui, Japan) after scanning the curve into a computer.

The impact speed of the Izod impact tester, with a pressure of $20 \mathrm{~kg} / \mathrm{cm}^{2}$, was $335 \mathrm{~cm} / \mathrm{s}$, and was based on the theoretical speed of a dropped denture (Fig. 4). The energy absorbed was calculated using the following equation ${ }^{21)}$ using the swing rise angle $(\beta)$ to the opposite side.

$$
E=W \cdot R\left\{(\cos \beta-\cos \alpha)-\left(\cos \alpha^{\prime}-\cos \alpha\right)(\alpha+\beta) /\left(\alpha+\alpha^{\prime}\right)\right\}
$$

where, $W(\mathrm{~kg})$ is the weight of the hammer, $R(\mathrm{~cm})$ is the distance from the center of the rotating shaft to the center of gravity of the hammer, $\alpha$ is the lifting angle 


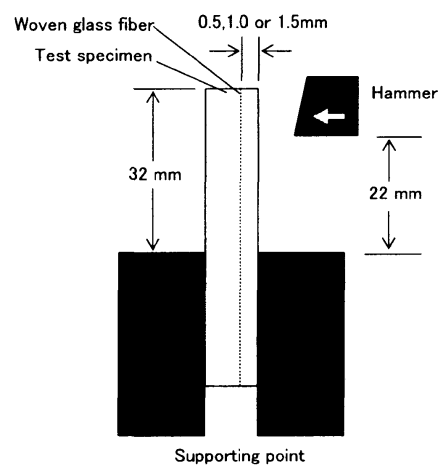

Fig. 4 Testing method of the Izod type impacttesting machine.

of the hammer, and $\alpha^{\prime}$ is the swing rise angle of a hammer swung without weight from the lifting angle $(\alpha)$. In all the tests, the test specimen was installed so that the glass fibers were under tension.

\section{Woven glass fiber content}

Test specimens were dried in an oven at $37^{\circ} \mathrm{C}$ for $24 \mathrm{hr}$, and weighed with an analytical balance. Then, the test specimen was soaked in tetrahydrofuran (THF) to dissolve the polymer. The remaining woven glass fiber was removed from the THF, dried, and then fired in a porcelain crucible at $600^{\circ} \mathrm{C}$ for $1 \mathrm{hr}$. The woven glass fiber was reweighed after it had cooled. The woven glass fiber content as a percentage by volume $\left(V_{g}\right)(\operatorname{vol} \%)$ was calculated using the following formula ${ }^{21)}$ :

$$
V_{g}=\left(W_{g} / r_{g}\right) /\left(W_{g} / r_{g}+W_{r} / r_{r}\right)
$$

where $W_{g}$ is the relative weight of the woven glass fiber, $r_{g}$ is the density of the woven glass fiber $\left(2.56 \mathrm{~g} / \mathrm{cm}^{3}\right), W_{r}$ is the relative weight of the polymer matrix, and $r_{r}$ is the density of the polymer matrix $\left(1.19 \mathrm{~g} / \mathrm{cm}^{3}\right)$.

\section{Statistical analysis}

Six specimens were used for each impact test. For controls, test specimens containing no woven glass fiber were made using the same method. A one-way analysis of variance (ANOVA) and Tukey's test were used to compare the differences in impact strength at $\alpha=0.05$.

\section{RESULTS}

None of the test specimens reinforced with single (S-05 and S-10) or double (D-05 and D-10) layers of woven glass fiber 0.5 or $1.0 \mathrm{~mm}$ below the surface fractured at an impact speed of $13.5 \mathrm{~cm} / \mathrm{s}$ (Fig. 5). In test specimens reinforced with single (S-15) or double (D-15) layers of woven glass fiber $1.5 \mathrm{~mm}$ from the surface, the absorbed 


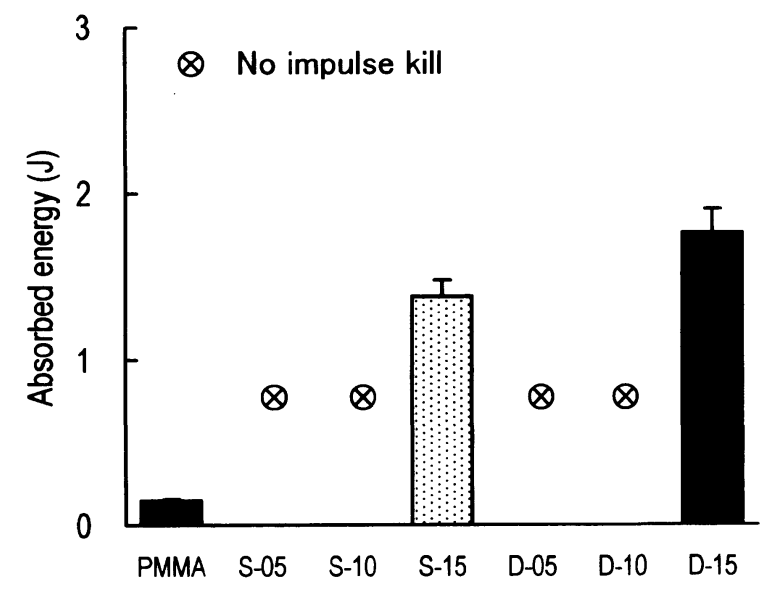

Fig. 5 Absorbed energy measured at the test speed of $13.5 \mathrm{~cm} / \mathrm{s}$ using the flywheel type impacttesting machine. Vertical bars indicate the standard deviation.

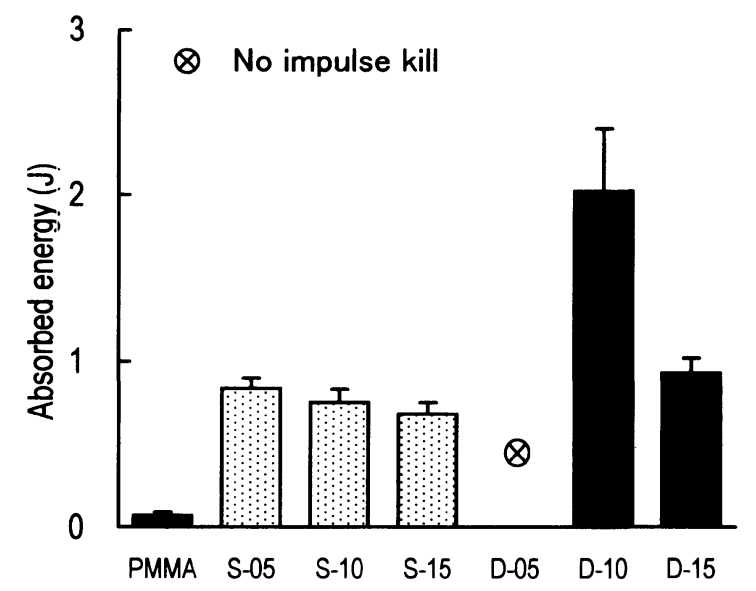

Fig. 6 Absorbed energy measured at the test speed of $75.0 \mathrm{~cm} / \mathrm{s}$ using the flywheel type impacttesting machine. Vertical bars indicate the standard deviation.

energy for breakage was 1.38 and $1.76 \mathrm{~J}$, respectively. The absorbed energy of the unreinforced resin (PMIMA) was $0.147 \mathrm{~J}$, and was significantly different from S-15 and D-15 $(p<0.05)$.

When the impact speed was $75.0 \mathrm{~cm} / \mathrm{s}$, the absorbed energy of S-05, S-10, and S15 was $0.84,0.75$, and $0.68 \mathrm{~J}$, respectively (Fig. 6). There was a significant difference between S-05 and S-15 $(p<0.05)$. The absorbed energy of D-10 and D-15 was 2.02 and $0.93 \mathrm{~J}$, while D-05 did not break at the maximum torque of this machine $(27.8 \mathrm{~N} \cdot \mathrm{m})$. 


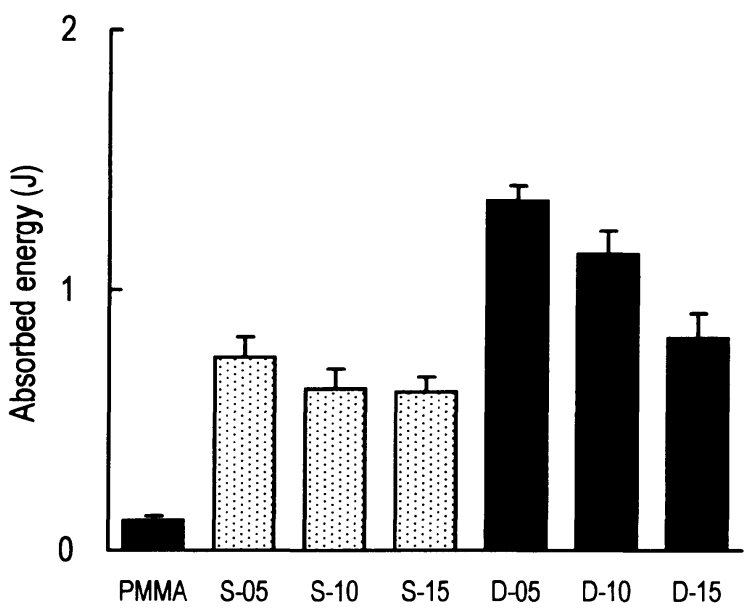

Fig. 7 Absorbed energy measured at the test speed of $335 \mathrm{~cm} / \mathrm{s}$ using the Izod type impacttesting machine. Vertical bars indicate the standard deviation.

The absorbed energy of PMMA was $0.07 \mathrm{~J}$ and differed significantly from all the measured values $(p<0.05)$.

At an impact speed of $335 \mathrm{~cm} / \mathrm{s}$, the absorbed energy of S-05, S-10, and S-15 was $0.74,0.62$, and $0.61 \mathrm{~J}$, respectively, and that of $\mathrm{D}-05, \mathrm{D}-10$, and $\mathrm{D}-15$ was $1.34,1.14$, and $0.82 \mathrm{~J}$, respectively (Fig. 7). There was a significant difference between S-05 and S-15 $(p<0.05)$. The absorbed energy of PMMA was $0.12 \mathrm{~J}$ and was significantly different from all the measured values $(p<0.05)$

The relative content of woven glass fiber when single and double layers were used was 3.8 and 7.8 vol\%, respectively.

\section{DISCUSSION}

A previous study ${ }^{22}$ clearly showed that the tensile strength of glass fiber must be increased to improve the impact strength of acrylic resin reinforced with glass fiber. Therefore, we used a new woven glass fiber, which is 5- fold stronger per unit width $(25 \mathrm{~mm}$ ) than the glass fiber used in the previous study. The increased strength of this woven glass fiber did not result from the strength of the glass itself, but from the increased quantity and diameter of its constituent filaments as a result of changing the weave of the fiber. Nevertheless, it was easily cut with scissors and there were no problems with its workability or bonding to the resin.

This study used two different testers. The first simulated breakage as a result of dropping the denture. The falling velocity $(V=362.6 \mathrm{~cm} / \mathrm{s})$ was calculated using the equation $V=(2 g h)^{1 / 2}$, where $\mathrm{g}=9.81 \mathrm{~m} / \mathrm{s}^{2}, h$ was the assumed height of a table $(70$ $\mathrm{cm}$ ), and air resistance was ignored. This speed closely matches the velocity (335 
$\mathrm{cm} / \mathrm{s}$ ) of the hammer of the Izod impact tester. In general, when a denture falls, conditions are unlikely to match the stresses in a two-point support test. Therefore, the Izod-type test was adopted in this study. The maximum absorbed energy with the Izod-type impact tester was about 11-fold (D-05) greater than that of PMMA. This is the first time the Izod impact strength of denture base resin reinforced with glass fiber has been determined; using carbon fiber, Shimozato et al. ${ }^{9}$ reported that the impact strength increased $200 \%$. Uzum ${ }^{19)}$ reported that the Charpy impact strength of resin reinforced with glass fiber was about 11-fold that of non-reinforced resin, and Vallittu et al ${ }^{18)}$ reported an approximately 10 -fold improvement in the impact strength when glass fibers were incorporated both near the surface and at the center of a resin specimen. These results agree with the present findings that the reinforcing effect of glass fiber measured using various impact tests is large.

We also carried out impact tests using a two-point support method, which models the stress causing breakage while chewing. Although the speed of chewing (13.5 $\mathrm{cm} / \mathrm{s}$ ) is $1 / 25$ that of falling, it is 4,000 times more rapid than that imposed in the general three-point bending test $(1-2 \mathrm{~mm} / \mathrm{min})$. However, no studies have measured the impact strength of denture base resin reinforced with glass fiber at this speed. At $13.5 \mathrm{~cm} / \mathrm{s}$, which corresponds to the speed during chewing, the S-15 and D-15 specimens broke, and the average impact strength was about 10 -fold greater than that of PMMA. Similarly, using the two-point support measurement, at an impact speed of $75 \mathrm{~cm} / \mathrm{s}$, D-10 was about 29 -fold stronger than PMMA, which was the greatest increase in strength measured.

When using a cornposite with a sandwich structure, a through examination is necessary, because the glass fiber content has a significant effect on the mechanical properties. Smith ${ }^{6)}$ reported that glass fiber is deleterious at contents of 20 vol\% or less, because the fibers act as weakening discontinuities. Vallittu ${ }^{15)}$ reported that a glass fiber content exceeding 14.8 vol\% has beneficial effects on tensile strength. Other studies ${ }^{14,17,18)}$ on its mechanical properties reported similar results. Woven glass fiber can be interwoven in the longitudinal and transverse directions. Deboer et $a .^{8)}$ measured the transverse strength when carbon fibers were incorporated parallel or perpendicular to an applied force, or in both directions, and found little benefit of parallel fibers on strength, although they did help to maintain shape. In contrast, Vallittu et al. ${ }^{14,17)}$ used glass fibers in all directions, and found that glass fibers perpendicular to the line of rupture prevented rupture, while the glass fiber content directly affected the strength of the reinforced resin. We also found that the impact strength measured by three test speeds increased with increasing fiber content, and the increase was greater when the woven glass fiber was placed near the surface. In examining the relationship between fiber content and impact strength, both Berrong et $a l{ }^{11)}$ and Taner et $a l^{13)}$ (using polyethylene fiber) and Gutteridge et $a{ }^{10,12)}$ (using Kevlar) reported that the impact strength increased with the fiber content. The fiber contents in our study were 3.8 and 7.8 vol\%, and are within the range of reported values. The present results demonstrate that relatively low glass fiber content sufficiently improves the impact strength in comparison with other mechanical properties. 


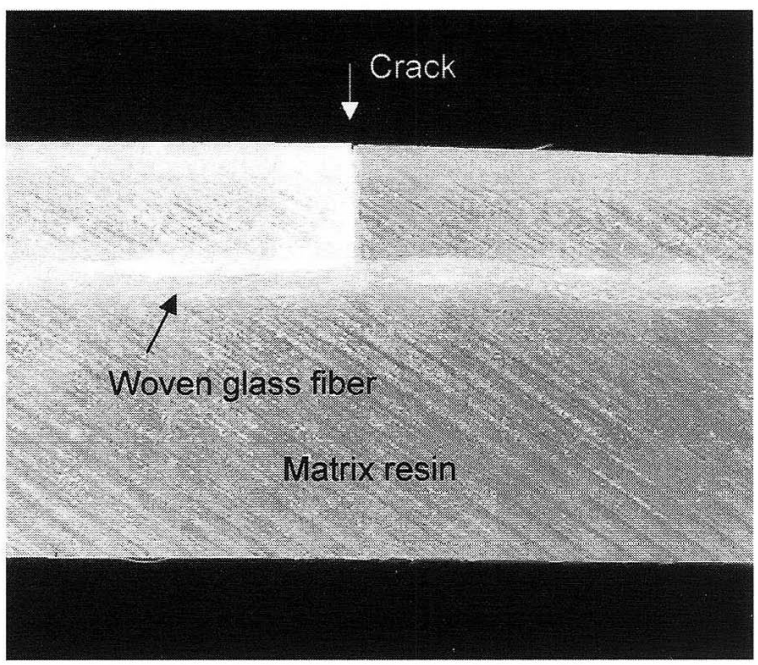

Fig. 8 A side view of $\mathrm{S}-10$ after impact test at the test speed of $13.5 \mathrm{~cm} / \mathrm{s}$.

In S-05 and D-05, the woven glass fiber was near the surface of test specimens, and these specimens were stronger than specimens $\mathrm{S}-15$ and $\mathrm{D}-15$, in which the woven glass fiber was placed in the center of the test specimens. This suggests that the position has an important effect on impact strength. The image of a fracture in Fig. 8 (S-10) shows that the crack in the matrix resin stops at the woven glass fiber, which clearly inhibits extension of the crack. Although glass is a brittle material, it clearly increases the impact resistance of dental resin. As described previously ${ }^{22)}$, this is accomplished by increasing the tensile strength of the reinforcing materials compared with the matrix resin at the point where a tensile force is applied. In specimens S-15 and D-15, the woven glass fiber was near the center of the specimen. Although this position does not necessarily increase strength in popular mechanical tests, such as the three-point bending strength, the woven glass fiber had a reinforcing effect in all impact conditions tested and the effect was greater when the fiber was in a more external position. In general, it is said to be difficult to incorporate a thin layer of glass fiber into a resin at a specific position; however, the present results suggest that even if the fiber is slightly misplaced, the impact resistance improves sufficiently.

\section{REFERENCES}

1) Hirasawa, T., Hirabayashi, S. and Harashima, I.: Studies of dental methacrylic resin (Part 8) Flexural and impact adhesive strength of self-curing methacrylic resin to crosslinked polymethyl methacrylate resins, J Jpn Soc Dent Appar Mater 22(60) : 299-305, 1981. (in Japanese)

2) Price, C. A.: The effect of cross-linking agents on the impact resistance of a linear poly (methyl methacrylate) denture-base polymer, J Dent Res 65(7): 987-992, 1986.

3) Rodford, R.: The development of high impact strength denture-base materials, $J$ Dent 
$14: 214-217,1986$.

4) Teshima, H. and Matsukawa, S.: A study on the improvement of denture base resin -Epoxy dimethacrylate-polybutadiene dimethacrylate-MMA monomers as the liquid of denture base resin--, $J J$ Dent Mater 9(4):509-519, 1990. (in Japanese)

5) Labella, R., Braden, M. and Davy, K. W. M.: Novel acrylic resins for dental applications, Biomater 13:13): 937-943, 1992.

6) Smith, D. C.: the non-metallic denture base-Recent developments, Dent Practitioner 8(3) : 73-80, 1957.

7) Kimura, H.: A study on the impact characteristics of carbon fiber prepreg reinforced dental P. M. M. A, J Osaka Univ Dent Sch $22:$ 43-47, 1982.

8) DeBoer, J., Vermilyea, S. G. and Brady, R. E.: The effect of carbon fiber orientation on the fatigue resistance and bending properties of two denture resins, $J$ Prosthet Dent 51(1) : 119-121, 1984.

9) Shimozato, T., Yamanaka, A., Kurata, S. and Yamazaki, N.: Denture base PMMA resins reinforced with carbon fibers Part 2 Effects of thickness and number of carbon fiber sheets on physical properties of reinforced specimen, $J J$ Dent Mate 3(6):797-801, 1984. (in Japanese)

10) Gutterridge, D. L.: The effect of including ultra-high-modulus polyethylene fiber on the impact strength of acrylic resin, Br Dent $J 164: 177-180,1988$.

11) Berrong, J. M., Weed, R. M. and Young, J. M.: Fracture resistance of Kevlar-reinforced poly (methyl methacrylate) resin: a preliminary study, Int $J$ Prosthodont 3(4) : 391-395, 1990.

12) Gutterridge, D. L.: Reinforcement of poly (methyl methacrylate) with ultra-high-modulus polyethylene fibre, J Dent 20(1): 50-54, 1992.

13) Taner, B., Doğan, A., Tinser, T. and Akinay, A. E.: A study on impact and tensile strength of acrylic resin filled with short ultra-high molecular weight polyethylene fibers, J Oral Sci 41(1): 15-18, 1999.

14) Vallittu, P. K., Lassila, V. P. and Lappalainen, R.: Acrylic resin-fiber composite -part I The effect of fiber concentration on fracture resistance, $J$ Prosthet Dent 71(6) : 607-612, 1994.

15) Vallittu, P.K.: Some aspects of the tensile strength of unidirectional glass fibrepolymethyl methacrylate composite used in dentures, J Oral Rehabil $25:$ 100-105, 1998.

16) Kanie, T., Arikawa, H., Fujii, K. and Ban, S.: Mechanical properties of reinforced denture base resin: The effect of position and the number of woven glass fibers, Dent Mater $J$ 21(3) : 261-269, 2002.

17) Vallittu, P. K., Vojtkova, H. and Lassila, V. P.: Impact strength of denture polymethyl methacrylate reinforced with continuous glass fibers or metal wire, Acta Odontol Scand 53 : 392-396, 1995.

18) Vallittu, P. K. and Narva, K.: Impact strength of a modified continuous glass fiber-poly (methyl methacrylate), Int $J$ Prosthodon 10(2): 142-148, 1997.

19) Uzun, G., Hersek, N. and Tinser, T.: Effect of five woven fiber reinforcements on the impact and transverse strength of a denture base resin, $J$ Prosthet Dent 81(5):616-620, 1999.

20) Oku, J.: Impact properties of acrylic denture base resin Part 1 A new method for determination of impact properties, Dent Mater $J 7(2): 166-173,1988$.

21) Plastics-Determination of Izod impact strength, JIS, K 7110-1971. (in Japanese)

22) Kanie, T., Fujii, K., Arikawa, H. and Inoue, K.: Flexural properties and impact strength of denture base polymer reinforced with woven glass fibers, Dent Mater 16 : 150158,2000 . 